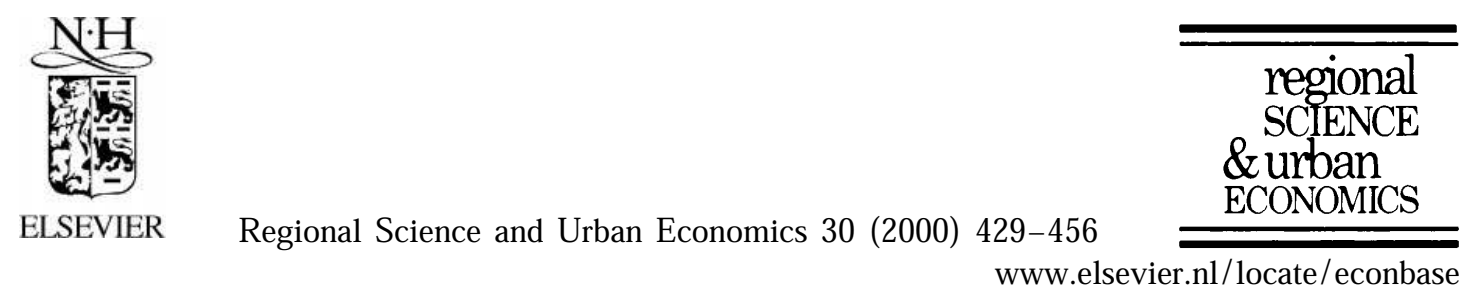

\title{
Delivered nonlinear pricing by duopolists
}

\author{
Cesaltina Pacheco Pires ${ }^{a, *}$, Soumodip Sarkar ${ }^{b}$ \\ ${ }^{a}$ Faculdade de Economia, Universidade Nova de Lisboa, Travessa Estêvão Pinto, 1099-032 Lisboa, \\ Portugal \\ ${ }^{\mathrm{b}}$ Universidade de Évora, Évora, Portugal
}

Received 31 July 1998; received in revised form 9 February 2000; accepted 16 March 2000

\begin{abstract}
This paper presents a model of delivered nonlinear pricing by duopolists operating in a linear city with two types of consumers and having incomplete information. At each location, the higher cost firm offers a uniform price equal to its delivered marginal cost while the lower cost firm offers a nonlinear tariff. For nearby locations, the lower cost firm may charge monopoly nonlinear prices, but as the distance increases the quantity consumed by the low valuation consumer becomes less inefficient than under monopoly. In the market region closest to the competitor's market we get an efficient outcome. If firms choose locations, before choosing tariff schedules, they will locate at the median of their equilibrium sales distribution. (c) 2000 Elsevier Science B.V. All rights reserved.
\end{abstract}

Keywords: Nonlinear pricing; Delivered pricing; Spatial competition

JEL classification: D43; D82; L13

\section{Introduction}

This paper presents a model where competing firms produce a good which is physically identical but spatially differentiated and where firms deliver the good. At each location, consumers may be of two types, high and low valuation, and firms have incomplete information about their types. We analyze how the

\footnotetext{
${ }^{*}$ Corresponding author. Tel.: +351-21-3801600; fax: +351-21-3886073.
}

E-mail address: cmp@fe.unl.pt (C.P. Pires) 